\title{
Antioxidant action of Rosemary extract in soybean oil submitted to thermoxidation
}

\author{
By Valéria C. Ramalho* and Neuza Jorge
}

\author{
Food Technology and Engineering Department - IBILCE - UNESP. \\ Rua Cristóvão Colombo, 2265 - CEP 15054-000 - \\ São José do Rio Preto - SP - Brasil. \\ *Corresponding author: valeria_ramalho@yahoo.com.br.
}

\section{RESUMEN}

Acción antioxidante del extracto de romero en el aceite de soja sometido a termoxidación

Este trabajo fue conducido para evaluar, en condiciones de termoxidación, la actividad antioxidante del extracto de romero añadido al aceite de soja. Fueron sometidos al calentamiento a $180^{\circ} \mathrm{C}$ tres tratamientos: aceite de soja purificado, aceite de soja refinado y aceite soja refinado añadido de $1.000 \mathrm{mg} / \mathrm{kg}$ de extracto de romero. Fue evaluada la evolución de la oxidación de las muestras después de $0 ; 2,5 ; 5$; 7,5 y 10 horas de termoxidación por medio de las determinaciones de la estabilidad oxidativa, compuestos polares totales y dienos conjugados. El aceite purificado difirió significativamente del aceite refinado, principalmente con relación a la estabilidad oxidativa debido a la remoción de los antioxidantes naturales. El extracto de romero presentó efecto antioxidante en alta temperatura. Después de 10 horas de calentamiento, $1.000 \mathrm{mg} / \mathrm{kg}$ de extracto de romero añadido al aceite de soja refinado aumentó significativamente la estabilidad oxidativa del aceite, de 7,52 para 13,50 horas y disminuyó la formación de polímeros y productos de descomposición medidos por medio del contenido de polares, de 17,35 para un 7,99\%. La formación de los productos primarios de oxidación medidos por medio del contenido de dienos también disminuyó de 1,61 para un $0,80 \%$. El extracto de romero podría ser indicado como un antioxidante alternativo en la conservación de aceites.

PALABRAS-CLAVE: Aceite de soja - Antioxidantes naturales - Especias - Estabilidad térmica - Extracto de romero.

\section{SUMMARY}

Antioxidant action of rosemary extract in soybean oil submitted to thermoxidation

This work was aimed at evaluating the antioxidant activity of rosemary extract added to soybean oil in thermoxidation conditions. Purified soybean oil, refined soybean oil and refined soybean oil containing $1,000 \mathrm{mg} / \mathrm{kg}$ rosemary extract were heated at $180{ }^{\circ} \mathrm{C}$. The oxidation of the samples was evaluated after $0,2.5,5,7.5$ and 10 hours of thermoxidation by means of oxidative stability determination, total polar compounds and conjugated dienes. The purified oil differed significantly from the refined oil, mainly in relation to oxidative stability due the removal of the natural antioxidants.
Rosemary extract presented antioxidant effects at high temperatures. After 10 hours of heating, $1,000 \mathrm{mg} / \mathrm{kg}$ rosemary extract added to the refined soybean oil significantly increased the oil oxidative stability from 7.52 to 13.5 hours and decreased the formation of polymers and decomposing products measured through the polar rates from 17.35 to $7.99 \%$. The build up of primary oxidation products gauged through diene rates also decreased from 1.61 to $0.80 \%$. Rosemary extract could be recommended as an alternative antioxidant.

KEY-WORDS: Natural antioxidants - Rosmarinus officinalis - Soybean oil - Spices -Thermostability.

\section{INTRODUCTION}

During the frying process, oils and fats are exposed to heat, air and moisture. These factors contribute to diminishing oil quality and changing the triacylglyceride structure. Moisture causes hydrolytic alteration; the temperature at which the operation takes place results in thermal alteration and, eventually, the air oxygen, which goes into the oil mass through the container surface, allows for oxidative alterations (Fritsch, 1981).

The thermoxidation process subjects oils or fats to high temperatures, similar to the frying process, but without the presence of food. Therefore, the temperature and the oxygen content are the variables that determine thermoxidation rates.

The presence of an antioxidant is one of the fastest ways to reduce fat oxidation (Karpinska et al., 2001) although, in their majority, antioxidants present little stability when exposed to high temperatures.

Experiments involving spice oxidation inhibition characteristics began in the 1950s. Researchers observed an increased oil stability in the presence of a variety of spices and condiments (Chipault et al., 1955). Within the spices, rosemary (Rosmarinus officinalis L.) is the one that presents the highest antioxidant ability. The compounds responsible for rosemary antioxidant activity are mainly phenolic diterpenes such as carnosol, carnosic acid, 
rosmanol, epirosmanol and isorosmanol (Cuvelier et al., 1994). Spice antioxidant activity is reduced once heated, probably because the phenolic antioxidant compounds either decompose or react with different substances in the test medium (Madsen and Bertelsen, 1995).

Che-Man and Jaswir (2000), reported that rosemary extract had strong antioxidant characteristic and good thermal stability. However, according to these authors, the information about rosemary extract effectiveness in delaying the deterioration of the oil during frying, as well as the phenolic diterpene degradation rate in these conditions seems to be limited.

The objective of this work was to evaluate the antioxidant potential of rosemary extract when added to soybean oil submitted to thermoxidation.

\section{MATERIALS AND METHODS}

Materials. Refined soybean oil free from antioxidant additions, supplied by Cargill Agricola S. A. (Uberlândia, Brazil) and commercial rosemary extract, supplied by Danisco S.A. (Cotia, Brazil) were used in this experiment. The composition of rosemary extract (Guardian ${ }^{\text {TM }}$ ), as declared by Danisco S. A., is $4 \%$ phenolic diterpenes and $96 \%$ mono and diglyceride fatty acids, triacetin and propylene glycol.

Soybean oil thermoxidation. Three oils were subjected to thermoxidation: refined soybean oil purified by means of adsorption chromatography on aluminium oxide for the removal of natural antioxidants following the method described by Steel and others (2005), the control (PSBO), refined soybean oil not purified with aluminium oxide, therefore bearing its natural antioxidants (RSBO) and refined soybean oil added with 1,000 $\mathrm{mg} / \mathrm{kg}$ rosemary extract (RSBO + RE).

The concentration of rosemary extract used was based on a preliminary study, where $1,000 \mathrm{mg} / \mathrm{kg}$ of such antioxidant promoted a higher oxidative stability in purified soybean oil as measured by Rancimat apparatus, within a range of 0 to 1,000 $\mathrm{mg} / \mathrm{kg}$. The limit of $1,000 \mathrm{mg} / \mathrm{kg}$ was chosen for this value to be the highest according to commercial recommendation. The rosemary extract was added directly to the oil, followed by slow stirring until complete dissolution.

The tests for thermoxidation of the treatments mentioned were carried out on a hot plate, using 50 $\mathrm{mL}$ beakers containing $30 \mathrm{~mL}$ of sample with a 0.4 $\mathrm{cm}^{-1}$ surface/volume ratio. This value corresponds to the one normally used for frying in a frying pan. The temperature was set at $180{ }^{\circ} \mathrm{C}$, normally used for deep frying. Heating was carried out continuously for $0,2.5,5,7.5$ and 10 hours. All the samples, at different intervals of time, were collected in amber flasks and stored at $-18^{\circ} \mathrm{C}$ until the time of analyses. All of the treatments were carried out in replicate.

Analytical methods. Antioxidant activities were assessed by means of oxidative stability determinations, total polar compounds and conjugated dienes.

Oxidative stability. Oxidative stability is expressed in hours and determined by AOCS Official Method Cd 12b-92 (1993), using a Rancimat apparatus (Metrohm, model 743), which is based on the determination of the electric conductivity of the volatile product degradation. The determination was made at $100{ }^{\circ} \mathrm{C}$ with a $20 \mathrm{~L} / \mathrm{h}$ air flow, using $3 \mathrm{~g}$ of the sample and $60 \mathrm{~mL}$ distilled water in flasks containing electrodes.

Total polar compounds. Total polar compounds are expressed as percentages and determined by the chromatography method proposed by Dobarganes et al. (2000). The basis of this method is the separation of oil samples using adsorption chromatography into two fractions of different polarities which can be measured gravimetrically.

Conjugated dienes. Conjugated dienes are expressed as conjugated diene acid percentages and measured by spectrophotometric determination as described in the AOCS Official Method Ti la-64 (1993).

Statistical analysis. Statistical analysis was performed taking into account the following factors: Oils (PSBO, RSBO, RSBO + RE) and Heating Times $(0,2.5,5,7.5$ and 10 hours). The results obtained from oxidative stability, total polar compounds and conjugated dienes, in replicate, determined once on each replication, were submitted to the analysis of variance in order to determine the factor influence on the alteration of the oils submitted to thermoxidation. The experiment was carried out in a $3 \times 5$ factorial scheme, using the completely randomized design (Gomes, 2000). Variance analyses, and, Turkey tests for the means at $5 \%$, were obtained by the ESTAT program - Statistical Analyses System version 2.0.

\section{RESULTS AND DISCUSSION}

Oxidative stability. The oxidative stability determined in the present work by Rancimat apparatus, is intrinsically influenced by the antioxidant presence which, likewise, is affected by high temperatures. It was observed, through variance analysis, that the oxidative stability was significant $(P<0.01)$ for the main effects and for the interaction, Oils $x$ Heating Times. Thus, the breakdown of this interaction (Table 1) was performed.

Regarding the heating times for each antioxidant, the purified oil oxidative stability values were not significantly different over the 10 hours (Table 1). This result makes evident that purification with aluminium oxide is efficient in removing natural antioxidants as the purified oil did not pose any resistance to oxidation from the beginning of heating.

Refined oil as well as refined oil with rosemary present a significant difference between oxidative 
Table 1

Mean values for oxidative Stability (hours) of oils heated up to 10 hours

\begin{tabular}{lccccc}
\hline \multirow{2}{*}{ Oils $^{\mathrm{a}}$} & \multicolumn{5}{c}{ Heating Times (hours) $^{\mathrm{b}}$} \\
\cline { 2 - 5 } & $\mathbf{0}$ & $\mathbf{2 . 5}$ & $\mathbf{5}$ & $\mathbf{7 . 5}$ & $\mathbf{1 0}$ \\
\hline PSBO & $0.48^{\mathrm{aC}}$ & $1.29^{\mathrm{aC}}$ & $0.93^{\mathrm{aC}}$ & $0.66^{\mathrm{aC}}$ & $0.60^{\mathrm{aC}}$ \\
RSBO & $17.08^{\mathrm{aB}}$ & $10.46^{\mathrm{bB}}$ & $9.86^{\mathrm{bB}}$ & $8.56^{\mathrm{CB}}$ & $7.52^{\mathrm{CB}}$ \\
RSBO + RE & $23.68^{\mathrm{aA}}$ & $15.80^{\mathrm{bA}}$ & $14.68^{\mathrm{bcA}}$ & $14.47^{\mathrm{CA}}$ & $13.50^{\mathrm{CA}}$ \\
\hline a (PSBO) - Purified soybean oil, (RSBO) - Refined soybean oil, \\
(RSBO + RE) - Refined soybean oil + 1,000 mg/kg rosemary \\
extract. \\
b Statistical (P < 0.05) difference between treatments (column) \\
and within treatments (rows) are represented as upper and \\
lower case letters respectively. Different letters represent \\
statistical differences.
\end{tabular}

stability values in the heating times 0 and 2.5 hours, both undergoing a remarkable reduction in the stability value in the latter time (Table 1). Although the oxidative stability values of the aforementioned oils have decreased along the course of the other times studied, this reduction was much less drastic over time. The refined oil stability was not significantly different between the heating times 2.5 and 5 hours, nor for the 7.5 and 10 hours. For the refined oil containing rosemary no significant differences between the oxidative stability at 2.5 and 5 hours, nor at $5,7.5$ and 10 hours were observed. At the end of 10 hours heating, refined oil and the same oil with rosemary retained 44 and $57 \%$ of their initial stability values respectively.

As for the oils, within each time, it was noticed that there was a significant difference between the oxidative stability values among the three treatments for all the heating times. In addition, the antioxidant action of rosemary was verified as an increase in oil stability over all heating times. When comparing the stability of the refined oil with the refined oil with rosemary, a 39\% increase in initial stability was observed in the oil containing rosemary. This increase was even more impressive after the 10 hours heating time as an $80 \%$ higher stability was observed.

Lalas and Dourtoglou (2003) also observed an increase in the oxidative stability of soybean oil upon adding $400 \mathrm{mg} / \mathrm{kg}$ rosemary extract, using Rancimat at $90{ }^{\circ} \mathrm{C}$. Our results support these observations.

Total polar compounds. The non polar fraction of the deteriorated oil and fats is made up of all unaltered TAG. The polar fraction includes all of the alteration products. As a result, the greater the polar fraction, the worse the oil quality.

The total polar compounds were significant $(\mathrm{P}<$ 0.01 ) for the principle effects as well as for the Oils $x$ Heating Times interaction. Therefore, the interaction breakdown was carried out (Table 2).

There was a significant difference between the total polar compound values of all heating times for each treatment (Table 2). An increase in the values was observed with increasing heating times for the
Table 2

Mean values for total polar compounds (\%) of oils heated up to 10 hours

\begin{tabular}{lccccc}
\hline \multirow{2}{*}{ Oils $^{\mathrm{a}}$} & \multicolumn{5}{c}{ Heating Times (hours) $^{\mathrm{b}}$} \\
\cline { 2 - 6 } & $\mathbf{0}$ & $\mathbf{2 . 5}$ & $\mathbf{5}$ & $\mathbf{7 . 5}$ & $\mathbf{1 0}$ \\
\hline $\mathrm{PSBO}$ & $0.12^{\mathrm{eB}}$ & $4.73^{\mathrm{dB}}$ & $8.73^{\mathrm{CA}}$ & $12.18^{\mathrm{bA}}$ & $17.13^{\mathrm{aA}}$ \\
RSBO & $1.98^{\mathrm{eA}}$ & $6.28^{\mathrm{dA}}$ & $9.23^{\mathrm{CA}}$ & $11.19^{\mathrm{bB}}$ & $17.35^{\mathrm{aA}}$ \\
RSBO + RE & $1.71^{\mathrm{AA}}$ & $4.46^{\mathrm{dB}}$ & $5.49^{\mathrm{CB}}$ & $6.87^{\mathrm{bC}}$ & $7.99^{\mathrm{aB}}$ \\
\hline
\end{tabular}

a (PSBO) - Purified soybean oil, (RSBO) - Refined soybean oil, $(\mathrm{RSBO}+\mathrm{RE})-$ Refined soybean oil $+1,000 \mathrm{mg} / \mathrm{kg}$ rosemary extract.

b Statistical $(P<0.05)$ difference between treatments (column) and within treatments (rows) are represented as upper and lower case letters respectively.

Different letters represent statistical differences.

three treatments. The oil containing rosemary had significantly lower polar compound formation.

There was a significant difference between the purified and refined oils total polar compound values at 0 and 2.5 hours of heating with the purified oil presenting a lower value; and 7.5 hours, with a lower value for the refined oil. There was no significant difference between the polar compound values of the two mentioned oils at the other times studied. Such an outcome, especially at the end of heating, was unexpected. The removal of natural antioxidants should have reduced the stability of the purified oil. The fact that the refined oil showed total polar compound values similar to those of the purified oil is an indication of the presence of a minority compound in the refined oil with prooxidant action which might have been removed in the purifying process.

Similar results to the ones of the present work for refined oil in the intermediate times were found by Cruzian et al. (1997). These researchers found 9.39, 10.40 and $11.80 \%$ polar compounds for soybean oil heated at $180^{\circ} \mathrm{C}$ for 4,6 and 8 hours, respectively. However, after 10 hours of heating, the value $(12.95 \%)$ found was less than the value observed in the present work. In a study to verify tocopherol loss and the degradation compounds in vegetable oils heated at $180{ }^{\circ} \mathrm{C}$, Barrera-Arellano et al. (2002) found $18.60 \%$ polar compound formation in refined soybean oil after 10 hours heating. This result was similar to the one found in the current study.

The total polar compound values of refined oil with rosemary differed from the others after 5 hours of heating and other subsequent times (Table 2). After the beginning of the heating, values were always lower than other oils, once again indicating the antioxidant effect of rosemary on soybean oil oxidation. After 10 hours of heating at $180^{\circ} \mathrm{C}$, rosemary extract prevented $54 \%$ of the total polar compound formation in refined oil.

Rosemary extract added at a concentration of $1,000 \mathrm{mg} / \mathrm{kg}$ also reduced, although in a smaller proportion, the formation of polar compounds in canola oil submitted to $180^{\circ} \mathrm{C}$ heating under frying conditions. When compared to a control, there was 
a polar compound reduction of $7 \%$, after 12 potato frying operations for 5 minutes (Zandi and Gordon, 1999).

Conjugated dienes. According to Silva et al. (1999), the polyunsaturated fatty acid oxidation occurs with the formation of hydroperoxides and the double bond displacement followed by the formation of consequent conjugated dienes. Due to their instability, peroxides are broken down and thus the presence of conjugated dienes is a better measurement because they remain in the frying oil (Cella et al., 2002).

The conjugated dienes were significant $(P<$ $0.01)$ for the main effects as well as for the Oils $x$ Heating Times interaction. So, the breakdown of this interaction was necessary (Table 3).

The same behavior depicted previously for polar compounds, that is, an increase in the conjugated dienes rate showing significant differences among these oils was observed (Table 3). At each heating time, it is seen that, despite not having significant differences in conjugated diene values at time 0 , there was a significant difference in values among the three oils for all the other times studied. In comparing the formation of conjugated dienes of the refined oil with the purified oil, it was noticed that in the 2.5 hours heating time, the refined oil presented a higher value but in the subsequent times, the purified oil had higher conjugated diene rates. Lower diene values were found for the refined oil with rosemary during all the heating times after time 0 . This fact makes evident once again that rosemary extract had antioxidant characteristics when applied to soybean oil, even at high temperatures.

In a research carried out by Frankel et al. (1996) to assess the antioxidant activity of rosemary in several oil types, a rosemary extract containing $44 \mathrm{mg} / \mathrm{kg}$ carnosic acid and $6 \mathrm{mg} / \mathrm{kg}$ carnosol, added to soybean oil at a concentration of $1,000 \mathrm{mg} / \mathrm{kg}$, did also inhibit diene formation when compared to a control. In this case, the oxidation process was accelerated in an oven at $60^{\circ} \mathrm{C}$, for 20 days. In the present work, rosemary extract prevented diene formation in soybean oil after undergoing heating for 10 hours at $180^{\circ} \mathrm{C}$.

Table 3

Mean values for conjugated dienes (\%) of oils heated up to 10 hours

\begin{tabular}{lccccc}
\hline \multirow{2}{*}{ Oils $^{\mathrm{a}}$} & \multicolumn{5}{c}{ Heating Times $^{(\text {hours) }}{ }^{\mathrm{b}}$} \\
\cline { 2 - 6 } & $\mathbf{0}$ & $\mathbf{2 . 5}$ & $\mathbf{5}$ & $\mathbf{7 . 5}$ & $\mathbf{1 0}$ \\
\hline PSBO & $0.23^{\mathrm{eA}}$ & $0.63^{\mathrm{dB}}$ & $1.01^{\mathrm{cA}}$ & $1.32^{\mathrm{bA}}$ & $1.74^{\mathrm{aA}}$ \\
RSBO & $0.26^{\mathrm{eA}}$ & $0.68^{\mathrm{dA}}$ & $0.90^{\mathrm{CB}}$ & $1.03^{\mathrm{bB}}$ & $1.61^{\mathrm{aB}}$ \\
RSBO + REE & $0.26^{\mathrm{eA}}$ & $0.47^{\mathrm{dC}}$ & $0.59^{\mathrm{cC}}$ & $0.70^{\mathrm{bC}}$ & $0.80^{\mathrm{aC}}$ \\
\hline
\end{tabular}

a (PSBO) - Purified soybean oil, (RSBO) - Refined soybean oil, $(\mathrm{RSBO}+\mathrm{RE})-$ Refined soybean oil $+1,000 \mathrm{mg} / \mathrm{kg}$ rosemary extract.

b Statistical $(P<0.05)$ difference between treatments (column) and within treatments (rows) are represented as upper and lower case letters respectively.

Different letters represent statistical differences.
In conclusion, the addition of rosemary extract to natural soybean oil showed a positive effect on the oxidative and thermal stabilities of such raw material and could be recommended as an alternative antioxidant in oil conservation.

\section{REFERENCES}

AOCS. 1993. Official Methods and Recommended Practices of the American Oil Chemists' Society. Champaign: AOCS Press.

Barrera-Arellano D, Ruiz-Méndez V, Velasco J, MárquezRuiz G, Dobarganes C. 2002. Loss of tocopherols and formation of degradation compounds at frying temperatures in oils differing in degree of unsaturation and natural antioxidant content. J. Sci. Food Agric. 82, 1696-1702

Cella RCF, Regitano-D'Arce MAB, Spoto MHF. 2002. Refined soybean oil performance in vegetable deepfat trying. Ciênc. Tecnol. Aliment. 22, 111-116.

Che-Man YB, Jaswir I. 2000. Effect of rosemary and sage extracts on frying performance of refined, bleached and deodorized (RBD) palm olein during deep-fat frying. Food Chem. 69, 301-307.

Chipault JR, Mizuno GR, Lundberg WO. 1955. Antioxidants properties of spices in oil-in-water emulsions. Food Res. 20, 443-448.

Cruzian JL, Inhamuns AJ, Barrera-Arellano D. 1997. Determination of polar compounds by TLC-FID in refined and partially hidrogenated soybean heated oils. Grasas Aceites 48, 148-153.

Cuvelier ME, Berset C, Richard H. 1994. Antioxidant constituents in sage. J Agric. Food Chem. 42, 665-669.

Dobarganes MC, Velasco J, Dieffenbacher A. 2000. Determination of polar compounds, polymerized and oxidized triacylglycerols, and diacylglycerols in oils and fats. Pure Appl. Chem. 72, 1563-1575.

Frankel EN, Huang SW, Prior E, Aeschbach R. 1996. Evaluation of antioxidant activity of rosemary extracts, carnosol and carnosic acid in bulk vegetable oils and fish oil and their emulsions. J. Sci. Food Agric. 72, 201-208.

Fritsch CW. 1981. Measurements of frying fat deterioration: a brief review. J. Am. Oil Chem. Soc. 58, 272-274.

Gomes FP. 2000. Statistical experiment course. Piracicaba: Nobel. 477 p.

Karpinska M, Borowski J, Danowska OM. 2001. The use of natural antioxidants in ready-to-serve food. Food Chem. 72, 5-9.

Lalas S, Dourtoglou V. 2003. Use of rosemary extract in preventing oxidation during deep-fat frying of potato chips. J. Am. Oil Chem. Soc. 80, 579-583.

Madsen HL, Bertelsen G. 1995. Spices as Antioxidants. Trends Food Sci. Technol. 6, 271-277.

Silva FAM, Borges MFM, Ferreira AA. 1999. Methods for the evaluation of the degree of lipid oxidation and the antioxidant activity. Quím. Nova 22, 94-103.

Steel CJ, Dobarganes MC, Barrera-Arellano D. 2005. The Influence of natural tocopherols during thermal oxidation of refined and partially hidrogenated soybean oils. Grasas Aceites 56, 46-52.

Zandi P, Gordon MH. 1999. Antioxidant activity of extracts from old tea leaves. Food Chem. 14, 285-288.

Recibido: 26/07/07 Aceptado: 26/11/07 